\title{
Unknown effects of social innovations
}

\author{
Michael Zürn (1) \\ WZB Berlin Social Science Center, Berlin, Germany \\ Corresponding author. E-mail: michael.zuern@wzb.eu
}

(Received 19 June 2019; revised 4 December 2019; accepted 30 December 2019; first published online 13 August 2020)

\begin{abstract}
The omnipresence of radical uncertainty asks for a concept of causality that moves beyond the notion of predicted probabilities. Protean power is a most important contribution to move International Relations research in this direction. Yet, some of the key components need further grounding in existing concepts and debates. First, protean power should include the notion of directionality in order to be power. Second, it should allow for an analysis of the different forms of relation between protean power and different types of uncertainties. And it should focus on features of the power relationship instead of the context in which it takes place to be able to transfer it to contexts other than uncertainty.
\end{abstract}

Keywords: types of uncertainty; power; causes; context

It was in the late 1970s in a high school in the suburbs of Stuttgart, Germany, during an event organized by some of the young teachers of the new school that a group of scared and politicized pupils had a discussion with the scientists who defended nuclear energy and the building of nuclear plants. The experts defended nuclear energy not only for its economic and environmental advantages, but they also explored all conceivable scenarios, arguing for each of them that the nuclear plants were well protected. Whatever new scenario we came up with, the experts had a strong response. Suddenly, some of my friends stood up and said: 'It is impossible that you know all of the possibilities of what could happen. The most dangerous are those that we do not know'. This statement immediately changed the argumentative balance. It was not us anymore who had to prove that the worst case can happen, but them who had to prove the impossible: that they know the unknowns. The moment when the audience realized that uncertainty was involved, the argumentative power shifted. The scientists lost epistemic authority; so-called common sense took over. Although without having knowledge of the terms themselves, it was the first time that I had encountered the difference between risk and uncertainty - a few years before I learned about Knightian uncertainty, a decade before I read Ulrich Beck and Anthony Giddens, and four decades before I had the privilege to be on an International

(c) The Author(s), 2020. Published by Cambridge University Press. This is an Open Access article, distributed under the terms of the Creative Commons Attribution licence (http://creativecommons.org/licenses/by/4.0/), which permits unrestricted re-use, distribution, and reproduction in any medium, provided the original work is properly cited. 
Studies Association (ISA) roundtable on Peter Katzenstein and Lucia Seybert's book on Protean Power (2018a).

The episode demonstrates that I am deeply sympathetic to the idea that we need to have a conceptual apparatus in the social sciences that is better suited to work in contexts of uncertainty. Uncertainty is a game changer, and Protean Power is the book in International Relations (IR) that comes close to the ambitious goal of accounting for such change. It is a marvelous and thought-provoking book. It does especially three things very well: it develops the concept of protean power against the background of the distinction between risk and uncertainty; it shows the dynamics of protean power that are clearly different from the exercise of control power; and it offers compelling applications of the concept in the chapters that follow the conceptual chapters. The book digs deep. It insists that power is a relational concept and all social relations change when there is uncertainty. Under radical uncertainty, protean power comes into the play and works against control power. The connection is presented as a challenge for IR theory, which, according to Katzenstein and Seybert, fails to account for power processes under uncertainty since it focuses exclusively on control power and assumes to live in a world of risks without uncertainty. ${ }^{1}$

Against the background of these achievements, my remarks may appear small and even to some extent as nitpicking, especially since I agree with many of the most important ideas of the book. For instance, I strongly endorse the critique of those perspectives that consider social science mainly as a source of control power by providing knowledge about risks. Most social scientists indeed aim at assessing the average effect of causes - the risk that $\mathrm{y}$ happens if $\mathrm{x}$ is present by isolating factors from others. The explanation of real-world social events and phenomena, however, needs to bring together so many different conceivable causes and contingencies that all the knowledge about the average effect of causes often does not help. Complexity takes over, and complexity creates unknown interaction effects or effects of contingencies that scientists cannot know in advance. Radical uncertainty asks for a concept of social science that moves beyond the notion of predicted probabilities. To the contrary, we need to understand the causes of effects to explain complex patterns and events. Whereas I think that the notion of protean power has the potential to move IR research in this direction, some of the key components need further grounding in existing concepts and debates.

Thereby my general point addresses not only the book but also the field of IR in general. It is the concern that we are often trying to do things completely differently without sufficient consideration of important contributions to social theories outside of American dominated IR theory. Many of the important points in Protean Power could be developed even better by building on and specifying existing concepts without making strong claims about the need for another Copernican revolution. To be sure, the introductory chapters to the book do provide a discussion of other approaches, but it seems to lack the necessary depth and breadth at certain points. To illustrate this general point, I will focus on three conceptual issues.

\footnotetext{
${ }^{1}$ See Seybert and Katzenstein 2018b; Katzenstein and Seybert 2018b, 2018c.
} 


\section{On power and directionality}

Power is a relational concept - modern classics like Max Weber and Robert Dahl have made this utterly clear in their seminal definitions. In the words of Dahl $(1957,201)$, 'A has power over B to the extent that he can get B to do something that B would not otherwise do.' The relational feature of power was even more explicit in Weber's original definition: 'The probability within a social relationship of being able to secure one's own ends even against opposition'. ${ }^{3}$ The relational character of power is demonstrated by the failure of a robber who puts a gun against a person who is just in the process of committing suicide. The introduction emphasizes exactly this insight: power emerges only as the actualization of a potentiality. ${ }^{4}$ The resources are not power, they are only potentialities that need to be converted into power, and this depends on the relationship between the involved actors. It is this feature of power that is made so admirably clear in Protean Power.

While I fully agree with this understanding of power, I wonder whether the portrayal of my fellow IR scholars to be widely following 'a power as control over resources approach' is appropriate. Seybert and Katzenstein write: 'In the study of international politics, for example, power is widely understood to be about capabilities typically measured by indicators such as military spending, the size of the economy, or technological advancement; articles and books proceeding in this manner fill libraries. ${ }^{5}$ This reads as if David Singer is still the most influential theorist in IR. Most of these books in the mentioned libraries were published in the 1970s and 1980s - only a few hold on to this concept of power as control over resources. ${ }^{6}$ In contrast, current power theorists in IR mostly agree that the measurement of power via control over resources should not be conflated with the concept of power in general or even only with control power (social control is also a relational concept) as such. This is true for Liberals, Marxists, or critical approaches as well as for some Realists. Regarding the other dimension in mapping IR theories, the point becomes even clearer. Constructivists certainly agree with Katzenstein and Seybert. ${ }^{7}$ Even most rationalists trained with game theory also agree arguing that power evolves from a constellation of preferences and interests. It is not the case that certain preferences always fare better than others; it depends on the other preferences as well. ${ }^{8}$

The portrayal of the discipline as following a singular and somewhat simpleminded understanding of power, however, is not necessarily the core argument of Protean Power. It is only the juxtaposition of control power as capability-based and working under conditions of risk with protean power as relational and working under conditions of uncertainty that presses Seybert and Katzenstein to put the crowd in the capability-based box. ${ }^{9}$ While it follows the widespread practices to draw a picture of the discipline that is not very favorable, the novelty of their

\footnotetext{
${ }^{2}$ Dahl 1957, 201.

${ }^{3}$ Weber 1978, 656.

${ }^{4}$ See also Adler 2019.

${ }^{5}$ Seybert and Katzenstein 2018b, 6.

${ }^{6}$ E.g. Rosato 2012.

${ }^{7}$ See Barnett and Duvall 2005.

${ }^{8}$ Snidal 1985.

${ }^{9}$ Seybert and Katzenstein 2018b, 10.
} 
argument lies with 'working under conditions of uncertainty', not with focusing on relations.

The focus on uncertainty is the innovation in this book and the decisive point to focus on. Seybert and Katzenstein define protean power 'as the effect of improvisational and innovative responses to uncertainty that arise from actors' creativity and agility in response to uncertainty'. ${ }^{10}$ It is an elegant, complex, and innovative definition that seems to stand in the tradition of Foucault. In this line, the definition of protean power is full of qualifiers for the response: improvisation, innovative, taking place under conditions of uncertainty, and effective. So, it is a very specific type of response that is under question. But is it plausible to consider each effect of such a (qualified) response as power? I want to question whether the notion of power can be grasped by focusing on any effect of a specific type of response without adding any qualifiers to these effects.

To start with, there is little doubt that we need a broader understanding of power than suggested by Dahl. According to his definition, the exercise of power is an intentional act with which the power holder prevails over others. But this is only one face of power. As a second face of power, Bachrach and Baratz pointed to agenda setting procedures that exclude options in the interest of the powerful. ${ }^{11}$ Steven Lukes added a third face of power, a concept that can be labeled structural power. ${ }^{12}$ I would argue that these extensions of the concept of power are very useful, but they stop short of equating power with effects.

Compared to the conventional or Dahlian concept of power, protean power contains two extensions of the concept. Protean power depends neither on actor intentions (intentionality) nor on outcomes that are in line with the actor who exercises power in a relationship (directionality). Regarding intentionality, Seybert and Katzenstein argue that protean power often comes in an indirect mode of operation', thus not requiring intentionality. ${ }^{13}$ They emphasize the unintended consequences of otherwise rational actions. In freeing the notion of power from intentionality, they are in line with current understandings of power. Indeed, the whole point of the second and third face of power is to reduce the role of intentionality in the exercise of power. In structural power, for instance, the structure produces outcomes that are indicative of power relationships. If the structure of global competition for capital prevents certain national policies, this is a form of structural power that does not necessarily require intentional action on the side of the beneficiaries to produce beneficial outcomes. It is power without 'voice or signature'. ${ }^{14}$ In the discussion of Barnett and Duvall, structural and productive power works through the social relations of constitution instead of interactions of specific actors. ${ }^{15}$

The more radical move by Katzenstein and Seybert is to move power beyond directionality. It is not only the lack of intentions that characterize protean power, but the concept refers by definition to all effects of improvisational and innovative

\footnotetext{
${ }^{10}$ Seybert and Katzenstein 2018b, 4.

${ }^{11}$ Bachrach and Baratz 1977.

${ }^{12}$ Lukes 2005; see also Offe 1977.

${ }^{13}$ Seybert and Katzenstein 2018b.

${ }^{14}$ Butler 1997.

${ }^{15}$ Barnett and Duvall 2005.
} 
responses to uncertainty. In contrast, I want to maintain that directionality is a necessary feature of power. Without directionality, there is no power; without ideas or interests that are served or without a directed effect, the distinction between power and effect evaporates. Or, to put it in the words of James Dewey as cited in the conclusion, "[p] ower is the sum of conditions available for bringing the desirable into existence'. ${ }^{16}$ The global social structures, for instance, benefit some but not all, therefore pointing to power relationships. The structure of capitalism thus contains power since it systematically privileges capital over labor. If the structure of capitalism produced contingent effects without any systemic distributional consequences, I would not speak of structural power. More generally, in the absence of any directionality of effects, it seems to be impossible to speak about power.

To illustrate the point, let us move back from structures to agents. I am certainly able to take actions that influence my own goals and ideas negatively. For instance, although I desperately want my team to win in a soccer game, I may end up scoring an own goal. In this way, I influence the outcome of the soccer game significantly, but shooting oneself in the foot is not an exercise of power. Before we can speak of a power relationship, the effects of a response must be compatible with the ideas or interests of the respondent(s) or with the reproduction of a structure systematically favoring certain groups over others. In this understanding, a Foucauldian discourse may exert power as long as it systematically favors one group over others, but a Habermasian truth-seeking discourse does not. If directionality is not part of the definition of power, we equate effect and power. Such a widening of the concept of power seems to be normatively dangerous (since power becomes necessarily unavoidable and thus cannot be criticized) and empirically without explanatory grip.

Take, for instance, the volume's chapter on the guys who developed new derivatives in the financial markets - that is an innovative response under conditions of uncertainty. ${ }^{17}$ What they wanted in doing so is to earn money and possibly to evade regulatory power. They may have exercised protean power to the extent that they achieved this goal and maybe to the extent others followed their example. Is the ensuing production of a financial crisis protean power? According to the definition of protean power - 'the effect of improvisational and innovative responses to uncertainty $^{\prime 18}$ - this is because there is no qualifier of effect, and no directionality in line with the interests and ideas of those who innovate the response. If one considers directionality as part of power, then the production of a self-defeating crisis does not belong in the realm of power. The crisis may be an effect of power, but it is not an exercise of power.

Christian Reus-Smit concisely describes in his chapter in the volume on the evolution of rights from the perspective of protean power:

Undercurrents of change break the surface, and suddenly the impossible becomes real: long hostile public opinion swings, new institutional opportunities hand activists unexpected victories, coercion becomes counterproductive,

\footnotetext{
${ }^{16}$ Cited in Katzenstein and Seybert 2018a, 296.

${ }^{17}$ Lockwood and Nelson 2018.

${ }^{18}$ Seybert and Katzenstein 2018 b.
} 
opponents lose the will to fight what once was beyond the pale, and all of a sudden, what constitutes a recognized fundamental right transforms, or the category of humans entitled to such rights expands. ${ }^{19}$

Similarly, Rosa Parks, for instance, with her civil disobedience in 1955, exercised power by an innovative response to repression. She did it because she wanted to do something to change something else in a certain direction. And she was successful. But take, for instance, the students that organized the protests at Tiananmen Square in 1989. They produced an outcome that was not in their interest: increased repression by control power. My question therefore is whether the concept of power should not remain bound to effects in the desired direction. If any effect is power, then the question is why we need to distinguish between power and effect. In my view, power is a specific form of effect that involves systematic directionality. If we give up this specificity, the concept of power loses its distinction, and the Chinese butterfly causing a tornado exercises power somewhere else instead.

\section{On protean power and uncertainty}

If protean power were defined as effects of improvisational and innovative responses to uncertainty that are in line with the ideas and interests of the improvisers and innovators, the next question then is whether and how protean power differs from productive power, or whether it is operationalizing productive power while giving it a new name. Productive power can be defined as 'the constitution of all social subjects with various social powers through systems of knowledge and discursive practices of broad and general scope. ${ }^{20}$ In line with this definition of productive power, the case studies in Protean Power mostly refer to the capacity to adapt to new situations or to find solutions in an unknown situation. These powers can be destructive or constructive, depending on the perspective as the chapters in the volume show. Lockwood and Nelson, for instance, focus on the destructive power of financial products, while Reus-Smit focuses on constructive effects of protean power during the social rights revolutions. ${ }^{21}$ Similarly, in my reading of Barnett and Duvall, productive power can be destructive as well. The constitution of social subjects logically implies the destruction or at least nonconstitution of others. How then does protean power differ from productive power? According to Protean Power, the condition of uncertainty makes the difference: 'actors' creativity and agility [arise] in response to uncertainty'. ${ }^{22}$ Whereas the concept of productive power is not bound to uncertainty, protean power is. Regarding this conceptual move in Protean Power, I also have a question to raise.

Is it a good strategy to bind a certain type of activity (respectively a certain type of the exercise of power) conceptually to a specific situation? To be sure, many good theories specify situations and point to the social dynamics of such a situation. Take crises as an example. It is more or less established that time pressure, stress, and

\footnotetext{
${ }^{19}$ Reus-Smit 2018, 59.

${ }^{20}$ Barnett and Duvall 2005, 55.

${ }^{21}$ Lockwood and Nelson 2018, Reus-Smit 2018.

${ }^{22}$ Seybert and Katzenstein 2018b, 4.
} 
emotions play a more significant role when the situation is perceived as a crisis. It is therefore absolutely plausible to argue that protean power takes effect most often in situations of uncertainty. But Katzenstein and Seybert seem to go further: they bind protean power to uncertainty in definitional terms. Is it plausible to exclude protean power from a world that is perceived only in terms of risks? Are certain aspects of protean power not decisive in the evolution of societies, independent of their level of reflexivity about unknown unknowns?

In his chapter in the volume, Philip M. Ayoub analyzes another one: the navigation of uncertainty in the LGBT rights revolution. ${ }^{23}$ Again, the LGBT rights are a product of a long-standing struggle, but the success came with a rush. While it is true that LGBT proponents navigated under uncertainty, their responses certainly were not only to uncertainty but mainly to discrimination and repression. This illustrates the general question: Can protean power also be generated by control power instead of uncertainty? It seems to me that the (unjustified) exercise of power often brings at a certain but unknown point in time the barrel to overflow thus producing a rebellion or a revolution. Why should the provocation of such an overflow not count as protean power independent of the role of uncertainty? Does it make sense to exclude such responses to repression from the concept of protean power? I do not think so. In line with the tradition of thinking about power in relational terms, it seems desirable to think about features of the power relationships to classify power instead of features of the circumstance in which they take place. This does not exclude to think innovatively about the relationship between uncertainty and power, but the concept of power should be defined independently of its scope conditions. Scope conditions such as uncertainty are important, but they are often a matter of degree. Providing a typology of power that points to features of the concept instead of features of circumstances is also a way to avoid mind boggling questions such as why control power in circumstances of uncertainty is still control power.

\section{On uncertainty and risk}

Peter Katzenstein and Lucia Seybert move away from a dichotomous juxtaposition of risk and uncertainty. They elegantly introduce a second dimension between attributes of the underlying context and actor experience or perception of the world as risky and uncertain. The most severe case of uncertainty then is the one in which the objective world and the perceptions of the objective world converge (radical uncertainty). It is the context in which innovation is most urgent and most likely to be successful. Improvisation, in turn, is most likely when objective uncertainty goes together with actors perceiving the world as risky. In this sense, the realm of protean power - that is, the effect of improvisational and innovative responses is objective uncertainty (independent of actor experiences) as attribute of the underlying context.

This conceptualization raises the question of whether there can be anything else than protean power since objective uncertainty - as understood by Katzenstein and Seybert - always lingers in the background. Uncertainty as an attribute of the

\footnotetext{
${ }^{23}$ Ayoub 2018.
} 
underlying context is by definition omnipresent. Unknown unknowns cannot be known, but they can always pop up. Therefore, the shadow of unknown unknowns is always everywhere, meaning however that the decisive 'scope condition' for the different versions of power is invariant.

Again, it makes sense to build on pre-existing work on the role of uncertainty in our times. One well-known case is Ulrich Beck's (world) risk society. ${ }^{24}$ Without doubt, the arguments show parallels to some by Katzenstein and Seybert. The concept of risk society - which is close to the idea of radical uncertainty - however, is time-and-space-independent instead of bound to a ubiquitous concept. Most importantly, the amount of effects possibly produced by unknown unknowns (the degree of catastrophe) is part of the definition of risk society. Due to technological developments and the globalization of most social processes, Beck's unknown unknowns produce potentially horrific and potentially global outcomes. Nuclear energy is a prime example. While Beck acknowledges that epistemological uncertainty always restricted the idea of modernity, he introduces the difference between the first and the second modernity in which uncertainty becomes more important. It is then the second modernity that contains a constellation of technologies, institutions, practices, and attitudes that in turn also has implications for power relations. What Katzenstein and Seybert call protean power is in Beck's perspective subpolitics - a new form of politics that comes from below, does not use the formal channels of politics, but is nevertheless influential and sometimes powerful.

This little recourse to Ulrich Beck served to highlight my general question of why we need to bind protean power so directly to an invariant condition like objective uncertainty, which is a conditio humana. For instance, the very fine chapter about the Mexican-American border uses a broadened understanding of protean power effectively, but it does not necessarily need uncertainty to unfold the argument. ${ }^{25}$ Innovations and improvisations lead to social change (in the desired direction). But what is the relationship of those protean power activities to uncertainty? Similarly, the chapters on rights revolutions make clear that the subordinates do not always know what kind of repression will be used, but they do know that there is always a certain likelihood of repression when they struggle for their rights. Repression, therefore, seems to be a (high) risk. Each dictator, in turn, knows about the possibility of resistance. Does innovative resistance then fall into the category of radical uncertainty? Is it not risky from the perspective of the suppressed ones, or not a risk from the perspective of the power holder?

\section{Conclusion}

Protean power is a thought-provoking book that pushes the field to think more extensively about risk and uncertainty, and I am optimistic that it will achieve this goal as this Special Issue already indicates. It is a book that will still be in use for decades from now. Some will apply the framework, others will use it as a

\footnotetext{
${ }^{24}$ Beck 1986, 1999.

${ }^{25}$ Brigden and Andreas 2018.
} 
source of inspiration as I did here. In doing so, I argued for a conception of protean power that is more conventional and that sits easier with existing conceptualizations of relational power. I put forward three suggestions: protean power should include the notion of directionality in order to be power; it should not be bound definitionally to objective uncertainty in order to allow for an analysis of the different forms of relation between protean power and different types of uncertainties; and it should focus on features of the power relationship instead of the context in which it takes place to be able to transfer it to contexts other than uncertainty. Such changes in the concept would bind the new concept of protean power more closely to existing notions of relational power in the social sciences. Moving in this direction, I believe, could even extend the significant achievements of the book.

\section{References}

Adler, Emanuel. 2019. World Ordering: A Social Theory of Cognitive Evolution. Cambridge: Cambridge University Press.

Ayoub, Phillip M. 2018. "Protean Power in Movement: Navigating Uncertainty in the LGBT Rights Revolution." In Protean Power: Exploring the Uncertain and Unexpected in World Politics, edited by Peter Katzenstein and Lucia A. Seybert, 79-99. Cambridge: Cambridge University Press.

Bachrach, Peter, and Morton S. Baratz. 1977. Macht und Armut. Eine Theoretisch-Empirische Untersuchung. Frankfurt a.M.: Suhrkamp.

Barnett, Michael, and Raymond Duvall. 2005. "Power in International Politics." International Organization 59 (1): 39-75.

Beck, Ulrich. 1986. Risikogesellschaft. Frankfurt a.M.: Suhrkamp.

Beck, Ulrich. 1999. World Risk Society. Cambridge: Polity.

Brigden, Noelle K., and Peter Andreas. 2018. "Border Collision: Power Dynamics of Enforcement and Evasion Across the US-Mexico Line." In Protean Power: Exploring the Uncertain and Unexpected in World Politics, edited by Peter Katzenstein and Lucia A. Seybert, 100-23. Cambridge: Cambridge University Press.

Butler, Judith. 1997. Excitable Speech: A Politics of the Performative. London: Routledge.

Dahl, Robert A. 1957. “The Concept of Power.” Behavioral Science 2 (3): 201-15.

Katzenstein, Peter, and Lucia A. Seybert. 2018a. "Power Complexities and Political Theory." In Protean Power: Exploring the Uncertain and Unexpected in World Politics, edited by Peter Katzenstein and Lucia A. Seybert, 267-301. Cambridge: Cambridge University Press.

Katzenstein, Peter, and Lucia A. Seybert. 2018b. "Uncertainty, Risk, Power and the Limits of International Relations Theory." In Protean Power: Exploring the Uncertain and Unexpected in World Politics, edited by Peter Katzenstein and Lucia A. Seybert, 27-56. Cambridge: Cambridge University Press.

Katzenstein, Peter, and Lucia A. Seybert. eds. 2018c. Protean Power: Exploring the Uncertain and Unexpected in World Politics. Cambridge: Cambridge University Press.

Lockwood, Erin, and Stephen C. Nelson. 2018. "Incomplete Control: The Circulation of Power in Finance." In Protean Power: Exploring the Uncertain and Unexpected in World Politics, edited by Peter Katzenstein and Lucia A. Seybert, 166-87. Cambridge: Cambridge University Press.

Lukes, Steven. 2005. Power: A Radical View, 2nd ed. Houndsmills: Palgrave.

Offe, Claus. 1977. "Einleitung zu Macht und Armut." In Macht und Armut. Eine Theoretisch-Empirische Untersuchung, Peter Bachrach and Morton S. Baratz, Frankfurt a.M.: Suhrkamp, 7-34.

Reus-Smit, Christian. 2018. "Protean Power and Revolutions in Rights." In Protean Power: Exploring the Uncertain and Unexpected in World Politics, edited by Peter Katzenstein and Lucia A. Seybert, 59-78. Cambridge: Cambridge University Press.

Rosato, Sebastian. 2012. Europe United: Power Politics and the Making of the European Community. Ithaca, NY: Cornell University Press.

Seybert, Lucia A., and Peter Katzenstein. 2018a. "High-Tech: Power and Unpredictability at the Technological Frontier and in Bitcoin." In Protean Power: Exploring the Uncertain and Unexpected in 
World Politics, edited by Peter Katzenstein and Lucia A. Seybert, 124-44. Cambridge: Cambridge University Press.

Seybert, Lucia A., and Peter Katzenstein. 2018b. "Protean Power and Control Power: Conceptual Analysis." In Protean Power: Exploring the Uncertain and Unexpected in World Politics, edited by Peter Katzenstein and Lucia A. Seybert, 3-26. Cambridge: Cambridge University Press.

Snidal, Duncan. 1985. “The Game Theory of International Politics.” World Politics 38 (1): 25-57.

Weber, Max. 1978. Economy and Society: An Outline of Interpretive Sociology. Oakland, CA: University of California Press.

Cite this article: Zürn, M. 2020. "Unknown effects of social innovations." International Theory 12, 471-480, doi:10.1017/S1752971920000251 